\title{
A Low-Cost Technique for Radio-Tracking Wildlife Using a Small Standard Unmanned Aerial Vehicle
}

\begin{tabular}{|r|l|}
\hline Journal: & Journal of Unmanned Vehicle Systems \\
\hline Manuscript ID & juvs-2016-0021.R2 \\
\hline Date Submitted by the Author: & $16-$ Feb-2017 \\
\hline Complete List of Authors: & $\begin{array}{l}\text { Tremblay, Junior; Environment and Climate change Canada, Science and } \\
\text { Technology } \\
\text { Desrochers, André; Universite Laval, Centre d'étude de la forêt } \\
\text { Aubry, Yves; Environment and Climate change Canada, Canadian Wildlife } \\
\text { Service } \\
\text { Pace, Paul; Carleton University, } \\
\text { Bird, David M.; Campus of McGill University, Department of Natural } \\
\text { Resource Sciences Macdonald }\end{array}$ \\
\hline Keyword: & $\begin{array}{l}\text { unmanned aerial vehicule, radio-telemetry, Bicknell's thrush, Swainson's } \\
\text { thrush }\end{array}$ \\
\hline Please Select from this Special & N/A \\
\hline Issues list if applicable:
\end{tabular}




\title{
A Low-cost Technique for Radio-Tracking Wildlife Using a Small Standard Unmanned Aerial Vehicle
}

\author{
Junior A. Tremblay ${ }^{1}$, André Desrochers ${ }^{2}$, Yves Aubry ${ }^{3}$, Paul Pace ${ }^{4}$ and David M. Bird ${ }^{5}$. \\ ${ }^{1}$ Environment and Climate Change Canada, Sciences and Technology, 801-1550 Ave \\ d'Estimauville, Québec City, QC, G1J 0C3, Canada \\ ${ }^{2}$ Centre d'étude de la forêt Université Laval, 2405 rue de la Terrasse, Québec City, QC, G1V 0A6, \\ Canada \\ ${ }^{3}$ Environment and Climate Change Canada, Canadian Wildlife Service, 801-1550 Ave \\ d’Estimauville, Québec City, QC, G1J 0C3, Canada \\ ${ }^{4}$ Defense Research and Development Canada, 3701 Carling Avenue, Ottawa, ON, K1A OZ4 \\ ${ }^{5}$ Avian Science and Conservation Centre of McGill University, c/o 10980 Dunne Road, North \\ Saanich, BC V8L 5J1 Canada.
}




\begin{abstract}
Recent advances in using Unmanned Aerial Vehicles (UAV) to study wildlife offer promise and may improve data collection efficiency, and small UAVs such as multirotor platforms are suitable for this task because they are easy to deploy, can fly over terrain that is difficult to access on foot, and can be programmed to follow specific trajectories. The objective of our study was to determine whether a small UAV could be outfitted with a radio receiver to pick up signals from radio-transmitters worn by small forest birds (Catharus bickenilli and $C$. ustulatus). We compared radio-monitoring using an UAV and a ground-based vehicle. The detection of over $50 \%$ of the tagged birds in the $50 \mathrm{~m}$ altitude flights is indicative of the real potential of the concept. This is supported by a signal strength significantly stronger and more constant than ground-based signals. The signal receptor experienced no significant interference from the UAV electronics, thus enabling a "clean" set of detections from the birds. Based on these preliminary results, we conclude that UAVs can yield useable data from animals wearing light-weight transmitters. Radio-tracking bird with UAVs present a strong potential for applications in all types of forest stands, or even in the radio-tracking of multiple species or taxa.
\end{abstract}

Key words: Radio-telemetry, Bicknell's thrush Catharus bicknelli, Swainson thrush Catharus ustulatus, unmanned aerial vehicle.

\title{
Résumé
}

Les récents progrès de l'utilisation des véhicules aériens sans pilote (UAV) pour étudier de la faune sont prometteuses et peuvent améliorer l'efficacité de la collecte des données et de petits UAVs tels que les plates-formes multi-rotors sont intéressants car ils sont faciles à déployer, peuvent voler sur un terrain qui est difficile d'accès et peuvent être programmés pour suivre des trajectoires spécifiques. L'objectif de notre étude était de déterminer si un petit UAV pourrait être équipé d'un récepteur radio pour capter les signaux de radio-émetteurs portés par deux oiseaux forestiers (Catharus bickenilli et $C$. ustulatus). Nous avons comparé la radio-surveillance à l'aide d'un UAV et d'un véhicule au sol. La détection de plus de $50 \%$ des oiseaux marqués dans les $50 \mathrm{~m}$ vols d'altitude est une indication du potentiel réel de cette application. De plus, nous avons observé une intensité de signal plus forte et plus constante avec les survols d'UAV que les signaux obtenues à partir du sol avec un véhicule terrestre. Aucune interférence significative de l'électronique d'UAV n'a été remarquée, offrant ainsi un ensemble "propre» de détections des signaux des oiseaux. Sur la base de ces résultats préliminaires, nous concluons que les UAVs peuvent produire des données utilisables à partir d'animaux portant des émetteurs légers, au moins à des fins de détection. Les suivis par radio-surveillance avec les UAVs présentent un fort potentiel pour des applications dans tous les types de peuplements forestiers, et même dans la radio-surveillance d'espèces ou taxons multiples. 


\section{Introduction}

Small animals have been radio-tracked for more than half a century, leading to major advances in ecology (Kenward 1987, Millspaugh and Marzluff 2001). Traditional radio-tracking for terrestrial organisms requires experienced personnel and is labor-intensive (Mech and Barber 2002). For example, it usually requires circling potential target areas, often traveling several kilometers and manually adjusting antenna orientation and receiver gain to make a reading of the direction of the antenna with a hand-held compass. Besides labor-intensiveness, on-theground radio-tracking may yield biased results due to detection issues related to habitat structure, especially in the absence of trails or roads, but also to errors related to compass accuracy and/or reading (Rettie and McLoughlin 1999), signal strength and transmission quality (Kenward 1987).

Recent advances in using Unmanned Aerial Vehicles (UAV) to study wildlife (see review by Chabot and Bird 2015) offer promise and may improve data collection efficiency, especially in forested environments (Koh and Wich 2012). Small UAVs such as multirotor platforms are suitable for this task because they are easy to deploy, can fly over terrain that is difficult to access on foot, and can be programmed to follow specific trajectories. Furthermore, UAVs can operate at altitudes unlikely to disturb wildlife significantly (Drever et al. 2015).

The Bicknell's Thrush (Catharus bicknelli), a threatened bird species in Canada (Government of Canada 2012) and globally listed as vulnerable (BirdLife International 2012), would potentially benefit from the use of UAVs to document its movements in its breeding range. Indeed, the species breeds in high-elevation on northeastern North America forest dominated by dense, balsam fir (Abies balsamea) forest stands (Connolly et al 2002, Aubry et al 2011, 2016, Townsend et al. 2015), with generally $\geq 20,000$ stems/ha. The combination of rough terrain and very high density of balsam fir stems add to the aforementioned difficulties with the use of conventional, on-the-ground radio-tracking of Bicknell's Thrush. So far, there have been very few radio-tracking studies on the species on breeding grounds (Goetz et al. 2003, Aubry et al. 2011), which could be related to these difficulties.

Here, we look into the concept of using a radio-tracking system mounted on a small UAV to detect and locate small birds, i.e.Bicknell's and Swainson's thrushes (C. ustulatus), in dense balsam fir forest stands. Specifically, the objective of our study was to determine whether a small, off-the-shelf UAV could be outfitted with a similar radio receiver to pick up signals from radio-transmitters worn by the two thrush species. We compare radio-monitoring using an UAV and a ground-based vehicle. We also provide guidelines for the further development of UAVbased radio-tracking of forest birds.

\section{Material and Methods}

Study site 
The study was conducted at the Forêt Montmorency $\left(47^{\circ} 20^{\prime} \mathrm{N}, 71^{\circ} 07^{\prime} \mathrm{W}\right)$, Quebec, a research forest of $412 \mathrm{~km}^{2}$ that is managed for timber and recreational activities. The landscape is hilly, with elevations ranging from 600 to $1100 \mathrm{~m}$ (Darveau et al. 1997). The forest landscape is composed of regenerating forest stands of various ages, which are harvested primarily by the clear-cut method, as well as premature and mature stands. Mature forest in the study area is mostly second-growth dominated by balsam fir. Regenerating forest stands are dominated by balsam fir and white birch (Betula papyrifera), as well as planted white spruce (Picea glauca) and several fruit shrubs.

\section{Capture and tagging of birds}

From June $1^{\text {st }}$ to $29^{\text {th }} 2016$, we used arrays of mist nets to catch Bicknell's (BITH) and Swainson's (SWTH) Thrushes, and we fitted individuals with coded radio-transmitter (Avian NanoTag model NTQB-4-2, Lotek Wireless Inc., Newmarket, ON, Canada) using a figure-of-eight leg loop harness made of elastic thread (Rappole and Tipton 1991; Canadian Wildlife permit: SCFQ2016-02). The VHF transmitters operated at $166.380 \mathrm{MHz}$ (burst interval = $5.3 \mathrm{~s}$ ) with a unique identifier, had an approximate battery life of 163 days and weighed $1.0 \mathrm{~g}$ without harness material. Combined weight of the transmitter and harness material was $~ 1.15 \mathrm{~g}$, which was $4.1 \%$ of the mean body weight of BITH, and $3.8 \%$ for SWTH.

The radio receiver consisted of an omnidirectional dipole antenna coupled to a Funcube Pro+ Dongle linked to a USB Port Hub which was itself connected to a SensorGnome device (Compudata Systems, London, ON). Each tag has a specific coded burst and burst interval allowing the radio receiver system to monitor multiple transmitters on a single frequency 166.380 Mhz. To this end, thousands of tags can be simultaneously deployed and individually tracked within an array of radio receivers in North America, generally set up on Motus towers (http://motus.org). When a signal is detected, the georeferenced receivers logged the digitally coded transmitter ID, time of detection, signal strength and antenna on which the signal was detected. Detailed information on radio-receiver and nanotag configuration, and data processing of this technology can be obtained at http://sensorgnome.org.

The Unmanned Aerial Vehicle (UAV)

The UAV selected for the pilot project was the Sky Hero Spyder $X 8^{\circledR}$ with eight rotors and equipped with a gimbal suitable for small cameras. With a payload capacity of about $4 \mathrm{~kg}$ which includes the battery, this machine is controlled using a Pixhawk autopilot which allows for completely automated flight including take-off and landing. It is capable of following a preprogrammed way-point route, controlled and monitored from a tablet computer ground station. The aircraft can also be flown in a semi-manual mode using a standard radio controller. 
The receiver system (BeagleBone, FUNcube radio receiver and USB Port Hub) was mounted on a plate under the UAV (Figure 1). Power was supplied by a dedicated battery and a $5 \mathrm{~V}$ voltage regulator. A flexible omnidirectional dipole antenna was attached under the UAV. The receiver system and the antenna weighted $391.8 \mathrm{~g}$. For any specific tag, the signal should vary along the path with a maximum received signal strength received at closest proximity of the bird.

In practice the signal will be degraded by interferences from other emissions sources, multi-path effects, movement of the bird, and attenuation with distance to forest structure / cover types, drone interference with receiving signal, etc. However, an approximation of the point on the flight path of maximum signal strength can be made.

In this study, the UAV was flown on June $8^{\text {th }} 2016$ for four different surveys at an altitude of $50 \mathrm{~m}$ above ground on linear flight paths over forest patches near capture sites at a speed of $5 \mathrm{~m} / \mathrm{s}$.

As a comparison, we used the receiver system in a ground vehicle with a Tram 1154 3dB gain magnetic-mount omnidirectional antenna on its roof to monitor tagged thrushes during nestling stage. At this period, birds were assumed to move only over short distances, as they were tracked during the nestling stage of most breeding birds in the study area. In the case of thrushes, the nestling period starts approximatively June $05^{\text {th }}$ to July $31^{\text {st }}$ (Rousseu and Drolet 2015); we started this monitoring on June $22^{\text {nd }}$. We compared signal strengths of bird detection between UAV and ground vehicle using a paired t-test (McDonald 2014). We used R (v3.2.0; R Core Team 2015) for our analysis purposes, and differences were considered significant at $\alpha \leq 0.05$.

\section{Results and discussion}

Before the flight survey, 16 thrushes were caught and affixed with nanotags (6 BITHs and 10 SWTHs), and a total of 37 thrushes for all season. On the 4 UAV flights we made, four and five of the radio-tagged BITHs and SWTHs, respectively, (56\% - 9 / 16) were detected

(2.5 \pm 1.0 thrushes/flight). Comparatively, with the ground-based monitoring, the highest number of radio-tagged birds detected in a single day was $41 \%$ (15 / 37). Mean flight duration was $2.7 \pm 2.0 \mathrm{~min}$ and mean flight distance was $33.5 \pm 20.8 \mathrm{~m}$ (Table 1 ).

The detection of over $50 \%$ of the tagged birds in the $50 \mathrm{~m}$ altitude flights is indicative of the real potential of the concept (Figure 2). This is supported by a signal strength significantly stronger $(t=-8.862, \mathrm{df}=6, \mathrm{p}$-value $<0.001)$ and more constant than ground-based signals obtained from the ground with an omnidirectional antenna on a vehicle $(-98.1 \pm 1.7 \mathrm{dBm}$ for UAV surveys vs $112.0 \pm 3.9 \mathrm{dBm}$ for ground surveys). Despite the fact that the signal strength detected by the UAV and the ground monitoring vehicle were not obtained on the same days, the territorial birds were expected to remain close to their nesting site; therefore, this should not represent a major element to explain this difference. Also, omnidirectional antennas used were not identical 
(expected difference of $~ 3 \mathrm{dBm}$; B. Morton, Maple Leaf Communications, pers. comm.). Furthermore, differences in signal strengths between both methods need to be investigated, e.g. by deploying and surveying dummy tags in various habitat types.

The signal receptor experienced no significant interference from the UAV electronics, thus enabling a "clean" set of detections from the birds that were within range (estimated at $\leq 500 \mathrm{~m}$ ). Also, very short or stationary flights might be sufficient to detect birds, as suggested by our first survey which presented 4 bird detections, although the UAV only traveled $4.1 \mathrm{~m}$ (Table 1). Patterns of signal strength of non-stationary flights (Figure 2) do not clearly follow patterns we were expecting (signal vary along the path with a maximum received signal strength received at closest proximity of the bird), and this may due to the fact that many variables may influence detection patterns (bird position in tree (low or high), bird distance from the UAV, antenna orientation, tree density, etc.). Probably longer flight paths $(>50 \mathrm{~m})$ would have help to get better signal patterns as it would have offered more variations in signal strengths. More experimentations are needed to clarify detection patterns of signal strength, and eventually helping to estimate bird location. For instance, detections from two or more linear flight paths may be combined to get an estimate of the location of a bird of interest. Field trials are presently underway to determine an acceptable series of flight paths and flight speeds as a function of the terrain/landscape structure.

Previous studies report the potential of using unmanned aerial vehicle system to detect wildlife wearing VHF transmitters. However, these studies did not experiment on live animals (dos Santos et al. 2014, Cliff et al. 2015), while our study presents similar results but with live birds flying free in their natural environment. Furthermore, our system (Motus technology and a small UAV) is simpler to use and more affordable contrary to Cliff et al. (2015) who used a commercial UAV platform coupled with a recording ground station. While dos Santos et al. (2014) did use a similar system to ours, our results on live birds in nature confirmed their experimental findings collected under controlled conditions.

Based on these preliminary results, we conclude that UAVs, coupled with Motus receiver system, can yield useable data from simultaneous animals wearing light-weight transmitters (i.e. NanoTag model), at least for detection purposes, in dense balsam fir forest stands. Radiotracking bird with UAVs present a strong potential for applications in all types of forest stands, or even in the radio-tracking of multiple species or taxa, with probable higher efficiency in areas with thinner tree cover or more open habitats. Furthermore, our experiment highlights the higher efficiency of UAVs compared to doing ground-based monitoring with vehicles on forest roads. However, more experiments with UAVs are needed to precisely locate birds affixed with transmitters. To achieve this purpose, UAVs should be programmed to operate over longer flights, at a minimal speed of $5 \mathrm{~m} / \mathrm{s}$ to avoid bias due to movements of targeted individuals, and on transects spaced $50 \mathrm{~m}$ apart to ensure overlapping detection and possible triangulation. 


\section{Acknowledgements}

We are thankful to John Brzustowski and Stuart McKenzie from Bird Studies Canada, and Bob Morton from Maple Leaf Communications, for their technical assistance, and to the Forêt Montmorency staff for the logistical support.

\section{References}

Aubry, Y., Desrochers, A., and Seutin, G. 2011. Response of Bicknell's Thrush (Catharus bicknelli) to boreal silviculture and forest edges: a radio-tracking study. Canadian Journal of Zoology 89(6): 474-482. doi:10.1139/z11-011.

Aubry, Y., Desrochers, A., and Seutin, G. 2016. Regional patterns of habitat use by a threatened forest bird, the Bicknell's Thrush (Catharus bicknelli), in Quebec. Canadian Journal of Zoology 94: 301-309. dx.doi.org/10.1139/cjz-2015-0209.

BirdLife International. 2012. Catharus bicknelli. The IUCN Red List of Threatened Species 2012. Available from http://dx.doi.org/10.2305/IUCN.UK.2012-1.RLTS.T22728467A39707077 [accessed 22 July 2016].

Chabot, D., and Bird, D.M. 2015. Wildlife research and management methods in the 21st century: where do unmanned aircraft fit in? Journal of Unmanned Vehicle Systems 3(4): 137155. dx.doi.org/10.1139/juvs-2015-0021.

Cliff O.M., Fitch R., Sukkarieh S., Saunders D. L., and Heinsohn R. 2015. Online localization of radio-tagged wildlife with an autonomous aerial robot system. Proceedings of Robotics Science and Systems XI: 13-17.

Connolly, V., Seutin, G., Savard, J.P., and Rompré, G. 2002. Habitat use by the Bicknell's Thrush in the Estrie region, Quebec. Wilson Bull. 114(3): 333-341. doi:10.1676/0043-

5643(2002)114[0333:HUBTBT]2.0.CO;2.

Darveau M., Bélanger L., Huot J., Melançon E., and Debellefeuille, S. 1997 Forestry practices and the risk of bird nest predation in a boreal coniferous forest. Ecological Applications 7: $572-580$.

dos Santos G.A.M., Barnes Z., Lo E., Ritoper B., Nishizaki L., Tejeda X., Ke A., Lin H., Schurgers C., Lin A., and Kastner R. .2014. Small unmanned aerial vehicle system for wildlife radio collar tracking. In $11^{\text {th }}$ International Conference on Mobile Ad Hoc and Sensor Systems. p. 761-766.

Drever, M.C., Chabot, D., O'Hara, P.D., Thomas, J.D., Breault, A., and Millikin, R.L. 2015.

Evaluation of an unmanned rotorcraft to monitor wintering waterbirds and coastal habitats in British Columbia, Canada. Journal of Unmanned Vehicle Systems 3(4): 256-267. 
Goetz, J.E., McFarland, K.P., and Rimmer, C.C. 2003. Multiple paternity and multiple male feeders in Bicknell's Thrush (Catharus bicknelli). The Auk 120(4): 1044-1053.

Government of Canada. 2012. Species at Risk Act (SOR/2012-133). Canada Gazette 146: 14181629. Available from http://www.sararegistry.gc.ca/virtual_sara/files/orders/g2-14614i_e.pdf [accessed on 20 December 2016].

Kenward, R. 1987. Wildlife Radio Tagging. Academic Press, London, UK. 222 p.

Koh, L., and Wich, S. 2012. Dawn of drone ecology: low-cost autonomous aerial vehicles for conservation. Tropical Conservation Science 5(2): 121-132.

McDonald, J.H. 2014. Paired t-test. In Handbook of Biological Statistics. $3^{\text {rd }}$ ed. Sparky House Publishing, Baltimore, Maryland. p. 180-185.

Mech, L.D., and Barber, S.M. 2002. A critique of wildlife radio-tracking and its use in national parks. A critique of wildlife radio-tracking and its use in national parks. Biological Resources Management Division, US National Park Service, Fort Collins, CO Technical Report.

Millspaugh, J., and Marzluff, J.M. 2001. Radio tracking and animal populations. Academic Press, London, UK. 474 p.

R Core Team. 2015. R: A language and environment for statistical computing. R Foundation for Statistical Computing, Vienna, Austria. Available from http://www.R-project.org [accessed 12 August 2016].

Rappole, J.H., and Tipton, A.R. 1991. New harness design for attachment of radio transmitters to small passerines. Journal of Field Ornithology 62(3): 335-337.

Rettie, W.J., and McLoughlin, P.D. 1999. Overcoming radiotelemetry bias in habitat-selection studies. Canadian Journal of Zoology 77(8): 1175-1184.

Rousseu, F., and Drolet, B. 2015. Prédiction de la phénologie de nidification des oiseaux au Canada. Available from http://www.birdscanada.org/volunteer/pnw/rnest/index.jsp?lang=FR [accessed 24 August 2016]

Taylor, P.D., Crewe, T.L., Mackenzie, S.A, Lepage, D., Crysler, Z., Guglielmo, C.G., Hamilton, D.J., Holberton, R.L., Loring, P.H., Norris, D.R., Paquet, J., Ronconi, R.A., Smetzer, J., Welch, L., and Woodworth, B.K. The Motus Wildlife Tracking System: A collaborative research network to enhance the understanding of wildlife movement. Avian Conservation and Ecology, in review.

Townsend, J., McFarland, K.P., Rimmer, C.C., Ellison, W.G., and Goetz, J.E. 2015. Bicknell's Thrush (Catharus bicknelli), The Birds of North America. Available from http://bna.birds.cornell.edu/bna/species/592. doi:10.2173/bna.592 [accessed 22 July 2016] 
2 Table 1. Details of four flight surveys of an altitude of $50 \mathrm{~m}$ above ground on linear flight paths (speed of $5 \mathrm{~m} / \mathrm{s}$ ) over forest patches beside 3 capture sites of Bicknell's and Swainson's thrushes at the forêt Montmonrency (Québec, Canada).

\begin{tabular}{|c|c|c|c|c|c|c|c|c|}
\hline \multirow[b]{2}{*}{ Survey } & \multicolumn{2}{|c|}{ Hour } & \multirow{2}{*}{$\begin{array}{c}\text { Duration } \\
\text { (min) } \\
\end{array}$} & \multicolumn{2}{|c|}{ Location at start } & \multirow{2}{*}{$\begin{array}{c}\text { Flight } \\
\text { Distance } \\
(\mathrm{m}) \\
\end{array}$} & \multicolumn{2}{|c|}{ Ids detected } \\
\hline & Start & End & & Latitude & Longitude & & BITH & SWTH \\
\hline 1 & 09:50:34 & 09:52:57 & 2.4 & 47.38850 & 71.08283 & 4.1 & 435,442 & 446,451 \\
\hline 2 & 10:14:56 & 10:16:05 & 1.2 & 47.38262 & 71.08287 & 33.9 & & 429,430 \\
\hline 3 & 10:18:51 & $10: 24: 34$ & 5.7 & 47.38157 & 71.08287 & 45.9 & & 429,430 \\
\hline 4 & $15: 36: 53$ & $15: 38: 29$ & 1.6 & 47.34054 & 71.11554 & 50.3 & 431,432 & \\
\hline
\end{tabular}


7 Figure 1: Receiver system (from left to right: FUNcube Dongle radio receiver, USB Port Hub,

8 BeagleBone, and battery pack; antenna and GPS not shown on this picture) mounted on a plate 9 under the UAV.

10 Figure 2. Ground positions of signal detections during flights 2, 3, and 4 (top to bottom on left 11 panel, see Table 1 for details), coupled with signal strength proportional to symbol size (at left), 12 and patterns of signal strength (at right) for each bird detected by an UAV coupled with a 13 receiver system during the flights (mean altitude of $50 \mathrm{~m}$ at $5 \mathrm{~m} / \mathrm{s}$, and distance $>10 \mathrm{~m}$ ). 
$15 \quad$ Figure 1.

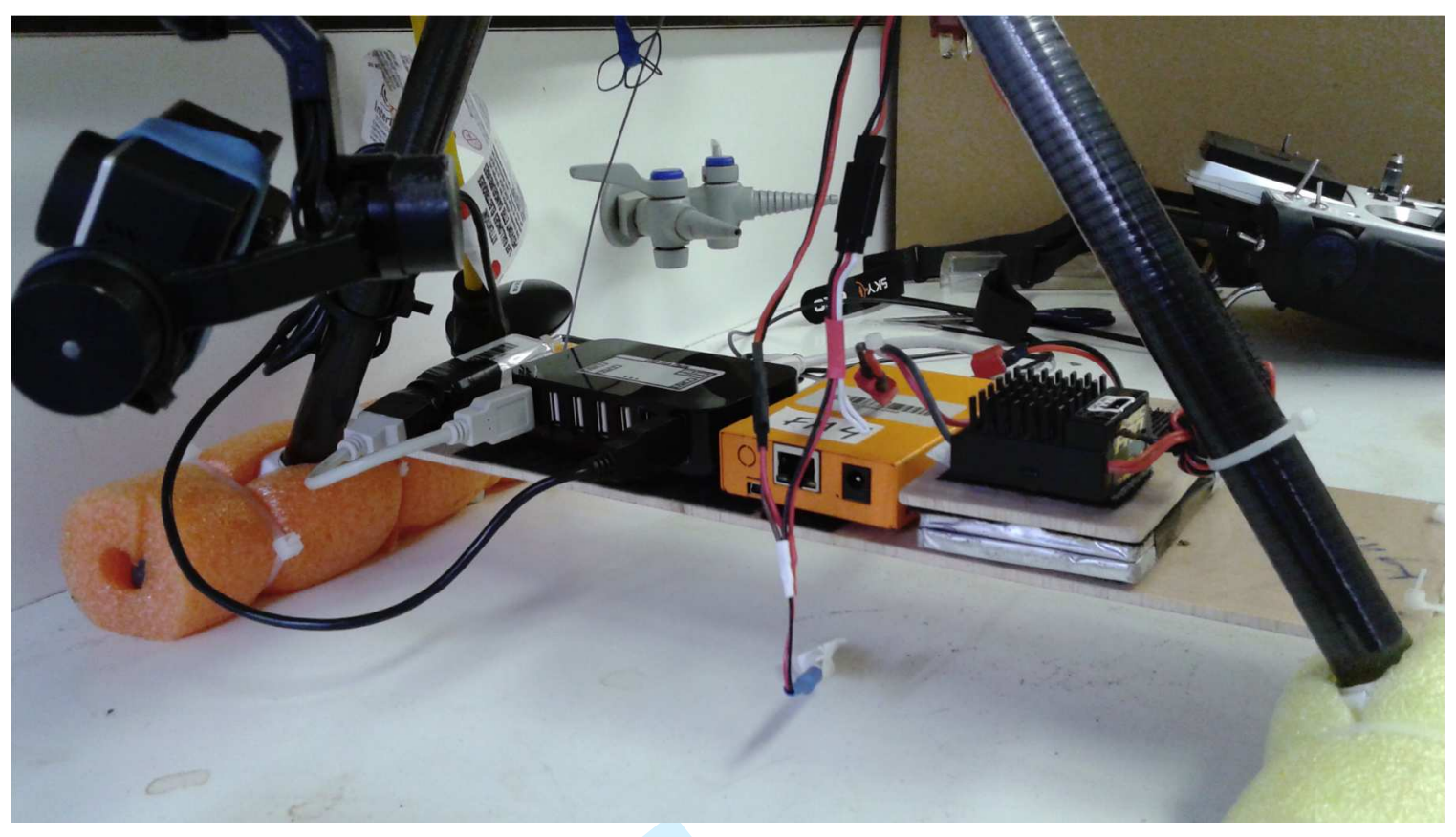

17 
Figure 2.
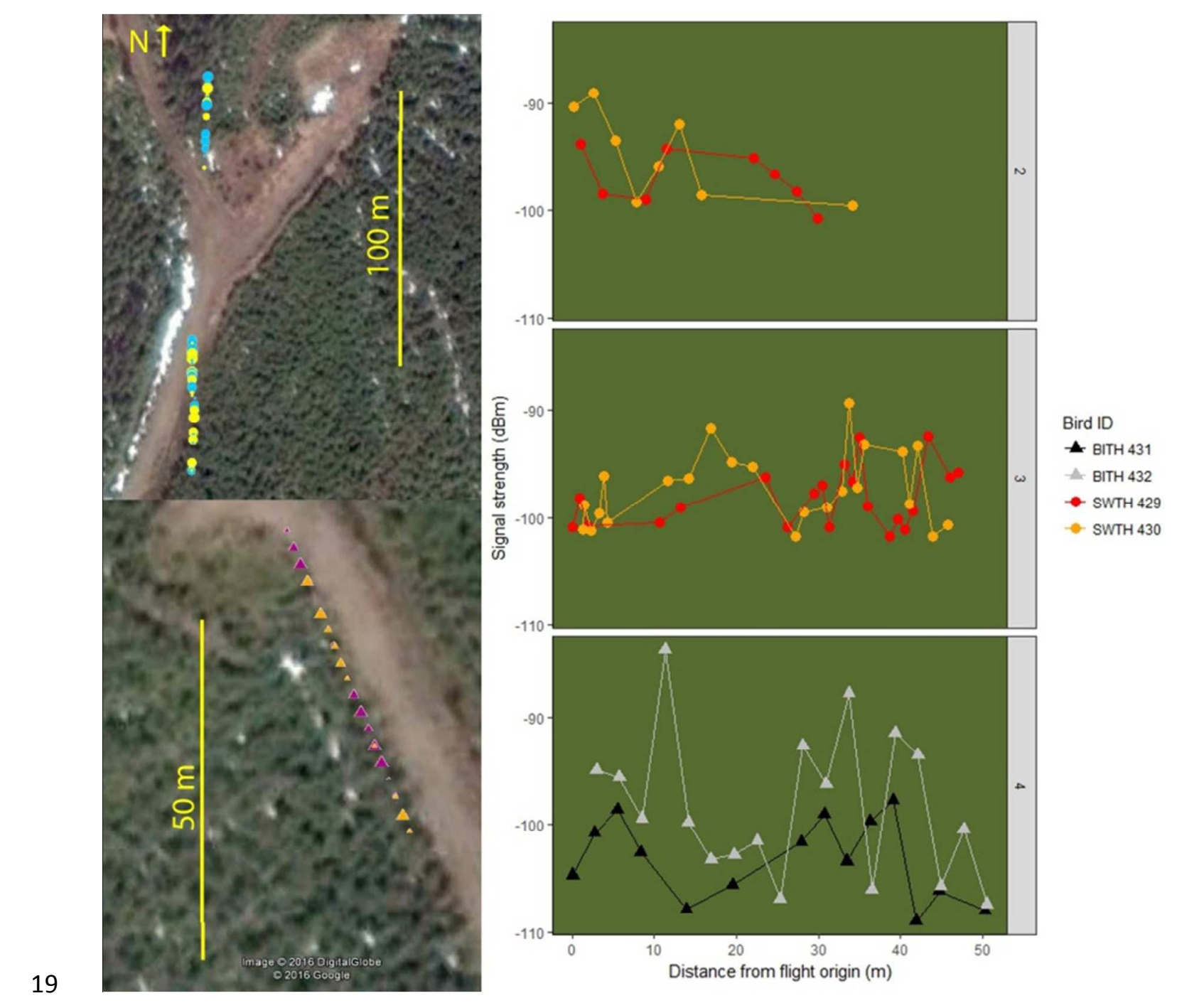